\title{
Review: light therapy is an effective treatment for seasonal affective disorder
}

Golden RN, Gaynes BN, Ekstrom RD, et al. The efficacy of light therapy in the treatment of mood disorders: a review and meta-analysis of the evidence. Am J Psychiatry 2005; 162:656-62.

\section{Is light therapy an effective therapy for seasonal affective disorder and non-seasonal depression?}

\section{METHODS}

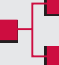

Design: Systematic review of randomised controlled trials (RCTs) with meta-analysis.

ㄴ.

Data sources: PUBMED searched from 1 January 1975 to 25 July 2003. Authors also searched MEDLINE, the Cochrane

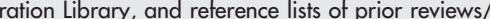
individual articles.

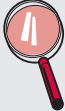

Study selection and analysis: The review included RCTs comparing phototherapy (either bright light therapy or dawn simulation) versus placebo in adults (18-65 years old) with a mood disorder (DSM-III, DSM-III-R, DSM-IV, Rosenthal criteria, or Research Diagnostic Criteria). For inclusion, bright light treatment had to consist of a minimum of four days of 3000 lux hours, with a maximum of 300 lux in the placebo group. Dawn simulation studies were included if they increased light from 0 to 200-300 lux over 1-2.5 hours, and the placebo group had fewer than 15 minutes of light or an increase of less than 5 lux. Standardised mean difference effect sizes were calculated for each study.

Outcomes: Measures of psychiatric symptoms (for example, Hamilton Depression Rating Scale); remission rates (criteria used for remission not stated).

\section{MAIN RESULTS}

Twenty three studies met inclusion criteria, and 20 provided sufficient data for meta-analysis. Compared to placebo, bright light treatment reduced the symptoms of seasonal affective disorder (eight RCTs; 360 people; effect size: $0.84,95 \%$ CI 0.60 to 1.08 ; $\mathrm{p}<0.0001$ ) and non-seasonal depression (three RCTs; 127 people; effect size: 0.53 , $95 \%$ CI 0.18 to $0.89 ; \mathrm{p}<0.003)$. Remission of seasonal affective disorder was almost three times more likely after bright light therapy than with placebo (four RCTs; OR 2.9, 95\% CI 1.6 to 5.4). Dawn simulation also improved the symptoms of seasonal affective disorder (five RCTs; 133 people; effect size: $0.73,95 \%$ CI 0.37 to $1.08, \mathrm{p}<0.0001$ ). No additional benefit was found for bright light therapy in conjunction with drug therapy in non-seasonal depression (five RCTs; 135 people; effect size: $-0.01,95 \%$ CI -0.36 to +0.34 , $\mathrm{p}>0.95$ ).

\section{CONCLUSIONS}

Phototherapy (bright light therapy or dawn simulation) is an effective treatment for seasonal affective disorder. Although bright light therapy reduces the symptoms of non-seasonal depression, it does not provide additional benefits when used as an adjunct to drug therapy.

For correspondence: Dr RN Golden, Department of Psychiatry Campus Box 7160, University of North Carolina at Chapel Hill, Chapel Hill, NC 275997160, USA; robert_golden@med.unc.edu

Sources of funding: none listed.

\section{NOTES}

It is difficult to define an appropriate inactive placebo for phototherapy. Placebo usually included some degree of light exposure in an attempt to blind participants to treatment condition.

\section{Commentary}

M eta-analyses such as these suffer from a paucity of completed studies eligible for inclusion at a time when large trials are in progress or completed too late for consideration. The conclusions are therefore vulnerable to quick reversal. Of the set reported here, the result for bright light for winter depression is strongest, with seven of eight randomised controlled trials (RCTs) showing benefit over placebo controls.

The meta-analysis of bright light for non-seasonal depression, although also positive in its conclusions, was based on only three RCTs. Further data are now available, ${ }^{1}$ and a revised Cochrane review is in preparation. Interestingly, the initial Cochrane review ${ }^{2}$ found that the most successful studies combined light with medication, whereas the present meta-analysis found no such advantage. That conclusion would now be reversed, given recently completed studies ${ }^{3} 4$ that show expedited improvement with fewer residual symptoms under combination treatment. The Committee on Chronotherapeutics of the International Society for Affective Disorders has issued a white paper encouraging adoption of this approach. ${ }^{5}$

The meta-analysis of dawn simulation for winter depression was based on four RCTs from a single centre (University of Washington, Seattle, US). Such an analysis cannot be conclusive, considering that centre and geographical differences cannot be assessed. Furthermore, the major study in the set-in which patients were also randomised into bright light therapy ${ }^{6}$ - found no bright light/placebo difference, which is a disturbing anomaly among the bright light studies. The good news is that a recent large trial in New York has found a significant $27 \%$ advantage in depression rating scale improvement under dawn simulation relative to a non-photic placebo (low density negative air ions). Furthermore, participants randomised to bright light showed a $34 \%$ advantage over placebo, not significantly different from the dawn simulation result.

Light therapy is the first among somatic interventions for depression to have evolved from physiological research, based on principles of photoperiodism and the circadian timing system. The positive assessment by the American Psychiatric Association work group chaired by Golden paves the way for clinical implementation in outpatients and inpatients alike. Michael Terman, PhD Department of Psychiatry, Columbia University and New York State Psychiatric Institute, New York, NY, USA

1 Goel N, Terman M, Terman JS, et al. Controlled trial of bright light and negative air ions for chronic depression. Psychol Med 2005;35:945-55.

2 Tuunainen A, Kripke DF, Endo T. Light therapy for non-seasonal depression. Cochrane Database Syst Rev 2004;2:CD004050.

3 Benedetti F, Colombo C, Pontiggia A, et al. Morning light treatment hastens the antidepressant effect of citalopram: a placebo-controlled trial. J Clin Psychiatry 2003;64:648-53

4 Martiny K. Adjunctive bright light in non-seasonal major depression. Acta Psychiatr Scand Suppl 2004;425:7-28.

5 Wirz-Justice A, Benedetti F, Berger M, et al. Chronotherapeutics (light and wake therapy) in affective disorders. Psychol Med 2005;35:939-44.

6 Avery DH, Eder DN, Bolte MA, et al. Dawn simulation and bright light in the treatment of SAD: a controlled study. Biol Psychiatry 2001;50:205-16.

7 Terman M, Terman JS. Controlled trial of naturalistic dawn simulation and negative air ionization for seasonal affective disorder. Am J Psychiatry (in press). 